\title{
Gender Differences in Predictive Validity of Kenyan Primary School Examinations in Secondary Schools
}

\author{
Eunice Atieno Agingu \\ PhD Student \\ Department of Educational Psychology, School of Education \\ Jaramogi Oginga Odinga University of Science and Technology (JOOUST) \\ P.O Box 210 - 40601 Bondo, Kenya
}

Tel: 254-712-258-240Ｅ-mail: agingueunice@ rocketmail.com

Received: November 24, 2017 Accepted: December 29, 2017 Published: February 5, 2018

doi:10.5296/gjes.v4i1.12602 URL: https://doi.org/10.5296/gjes.v4i1.12602

\begin{abstract}
The purpose of this study was to determine gender differences in predictive validity of Kenya Certificate of Primary Education (KCPE) among secondary school students in Kisii central Sub-county, Kenya. The study adopted Correlational and Ex-post-facto research designs. The study population was 3897 Kenya Certificate of Secondary Education (KCSE) candidates from 55 public secondary schools. Stratified random and saturated sampling techniques were used to select 16 secondary schools and 1391 students. Data used included $2006 \mathrm{KCPE}$ scores and 2010 KCSE scores of the same students under study. Data was collected using a researcher made pro forma. It was analyzed using correlations and regression analyses. Results showed a strong positive Pearson's correlation coefficient $(r=0.675 ; n=607 ; p<0.05)$ between KCPE and KCSE scores for male students and $(r=0.710 ; n=784 ; p<0.05)$ between KCPE and KCSE scores for female students. This was however not a statistically significant difference in correlation of KCSE and KCPE scores based on gender. The study concluded that KCPE scores is a good predictor of KCSE scores regardless of learners' gender. It recommended that both male and female learners should be accorded equal encouragement to improve their academic outcomes.
\end{abstract}

Keywords: Kenya Certificate of Primary Education (KCPE), Kenya Certificate of Secondary Education (KCSE), Predictive validity, Academic achievement (achievement in standardized tests) 


\section{Introduction}

Education system in Kenya, popularly referred to as 8-4-4 system, comprises eight years in primary school, four years in secondary school and four years in university. After eight years in primary school, learners are usually subjected to the first standardized national examination, the Kenya Certificate of Primary Education (KCPE). The scores in this examination are used to select learners to various cadres of secondary schools. After four years of secondary school education, learners sit for the second standardized national examination, the Kenya Certificate of Secondary Education (KCSE), used to select qualified students for various courses at the universities and other tertiary institutions.

In both KCPE and KCSE examinations, boys have been recording better outcomes compared to girls. Secondary data obtained from the government examining body, Kenya National Examination Council (KNEC) for a period of five years from 2007 to 2011 showed that boys were still scoring higher than girls in overall performance and across subjects in the KCSE (Kashu, 2014).

According to Hall (2015), whether or not past performance can predict future performance has been a highly debated issue, again with sex differences being considered. Hall reports that in a study which examined how home and motivational factors affected high school boys' and girls' academic achievement, researchers found that the best predictor of achievement was previous achievement. This was in agreement with studies conducted by Sacket, Kunal, Arneson, Cooper and Waters (2009, as cited in Hall, 2015) which stated that scores on admission tests were indeed predictive of academic performance as indexed by grades. This study by Hall reported a higher correlation between the predictor and criterion examination for male compared to female learners. It would therefore be important to investigate learners' gender differences on the relationship between previous achievement (KCPE scores) and future achievement (KCSE scores) in a different setting such as Kisii Central sub-county.

The question of gender differences in academic achievement in secondary schools in Africa is neither conclusive nor unanimous. In some countries such as Kenya, girls have lower academic achievement than boys, while in Mali, there is no difference in performance between boys and girls (Barthes, Nair, \& Malpade, 2000).

However, according to Mensch and Lloyd (1997), studies in Nigeria and Thailand have shown a higher achievement for girls in single sex schools relative to mixed schools but lower academic achievement for boys when schools with similar resources are compared. Due to the inconclusive findings on gender differences in academic achievement, it was necessary to investigate gender differences in the predictive validity of KCPE scores in Kisii Central sub-county.

In Kenya, a study conducted in Nyamira sub-county in Nyamira County, Ondima, Nyamasege, Mogwambo, and Ochoti (2013) reported that learners' performance in KCPE was very crucial in determining their final grade in KCSE. Depending on the institution learners were admitted to, they would improve, maintain or drop their grade. This study did not investigate the effect of learners' gender on the relationship between their KCPE and 
KCSE scores. A study was therefore necessary to determine gender differences on the nature and strength of the KCSE-KCPE relationship

On gender differences in academic achievement, there are reports of girls having a lower academic achievement than boys. Other studies however report higher academic achievement for girls than for boys. There is further no conclusive report on how past exam score predict future examination score differently for male and female learners.

Since KCPE examination score is accorded such a central role in selection of learners for secondary school education where it determines their fate with such finality, it was important to verify, through an empirical study its effectiveness based on gender, as a selection tool for secondary school education in Kisii Central Sub-County.

\section{Literature Review}

The question of whether there are gender differences in learners' academic achievement has been given a wide coverage the world over. However fewer correlational studies of past and future examination scores with consideration of the gender factor have been done. Hall (2015) in a study to examine the validity of secondary school entrance scores in predicting academic success of secondary school aged students, a positive relationship was found between the score on Barbados Secondary School Entrance Examination (BSSEE) and that of Caribbean Secondary Education Certificate (CSEE) for both males and females. In this study Hall further found that there was a higher correlation coefficient between BSSEE and CSEE for males than for females. Given that this study used a sample of 130 male and 122 female students, it was imperative to investigate the outcome of this relationship in Kenya and especially Kisii, using a larger sample size.

Ugwuda and Okechukwu (2013) carried out a study to examine the predictive validity of Nigerian Junior School Certificate Examination (JSCE) on students' achievement in Senior School Certificate Examination (SSCE) in which male students were found to perform better than female students in Igbo language and Math in JSCE while females performed better than males in social studies. In SSCE males performed better than females in all core subjects under investigation implying that gender was one of the determining factors in students' achievement in SSCE. The study further revealed that the predictive strength of JSCE on SSCE was significantly moderated by gender in all the subjects under investigation. Although this study considered the gender factor in the predictive validity of each core subject, it did not consider the gender factor in the aggregate JSCE and SSCE scores. This would be very important given that certificates are usually issued and used based on aggregate scores before scores on individual subjects are considered. This is why in the Kisii Central sub-county, the aggregate $\mathrm{KCPE}$ and KCSE scores were used when considering gender differences in the relationship between the two examinations.

In Tanzania, Komba, Kafanabo, Tryphone, and Kira (2013) investigated the predictive validity of Form Two Secondary Education Examination (FTSEE) on students' performance in the Certificate of Secondary Education Examination (CSEE) in Biology in which a higher relationship was observed for females between the two examinations than for males when the 
whole sample was considered. In this study the duration between the FTSEE and the CSEE was only two years. Again, both examinations were taken at secondary school level. Given that examinations are used for selection into the next level of learning, a predictive validity study should consider a primary school level examination as an independent variable. This would help preserve the few secondary school places available for only those who are likely to pass the secondary level examination.

In a study conducted by Jagero (2013) in one private school in Western Kenya, using a study sample of 110 students ( 82 boys and 28 girls) girls performed better in KCSE compared to boys although the girls were admitted to secondary school with a lower KCPE mean score compared to boys. The study further reported a higher predictive validity between KCPE and KCSE for girls than for boys. The sample in this study was not representative and therefore lacked external validity. According to Trochim (2006), external validity is the degree to which the conclusions in a study would hold for other persons in other places at other times. This, according to Trochim depends on the sample model used. If the sample is not representative of the population, the results cannot be generalized back to the population.

According to Makworo, Wasanga, and Olaly (2014) a report from Kenyenya in Kisii County indicated that girls' academic achievement at KCSE had been far lower than that of boys in the years 2009, 2010 and 2011. Further, no girl had scored a mean grade A or A- in the previous three years in the area. This was attributed to the girls' negative attitude towards their studies and negative academic self-concept. This study did not correlate girls' academic achievement at KCSE with an earlier grade to find out how well the earlier academic achievement of male and female learners predicted their future academic achievement. This would help planners and stake holders predict early enough the learners who were likely to pass or fail at KCSE examination.

In Kisii Central Sub-County, a study by Omenge and Nasongo (2010) in Mosocho Division concluded that though there was no significant gender difference between boys' and girls' academic achievement, the slightly higher mean score in favour of boys was attributed to the girls' frequent engagement in domestic chores compared to boys. This study was carried out in a single division, making the result less generalizable compared to one that would be carried out in the whole sub-county. Further to this, it did not correlate the academic achievement of the students under study with their earlier academic achievements, which would have shed light as to whether the low academic achievement of girls at KCSE was also related to their KCPE scores.

\section{Research Methodology}

\subsection{Research Design}

Correlational research design shows relationship between two variables thereby showing a cause and effect relationship (Rippy, 2012). It also shows predictions of future event or outcome from a variable. The advantage, according to Rippy (2012), is that it allows the researcher to analyze the relationship among a large number of variables. In addition, correlation co-efficient can provide for the degree and direction of relationships. In this study, 


\section{Macrothink}

Global Journal of Educational Studies

ISSN 2377-3936

2018, Vol. 4, No. 1

Correlational design was used to correlate KCPE and KCSE scores for the students under study where the dependent variable was the KCSE scores and the independent variable was the KCPE scores of the same students sampled for the study.

\subsection{Study Population}

The study comprised 3897 (2114 boys and 1783 girls) KCSE candidates of the year 2010 from 55 public secondary schools in Kisii Central Sub-County.

\subsection{Sampling Technique and Sample Size}

Two sampling techniques were used in this study. The first was stratified random sampling technique which was used to select 16 public secondary schools for the study and thereafter saturated sampling technique was used to select learners from each sampled school.

From the 16 selected schools, saturated sampling technique was used whereby scores for all KCSE graduates whose KCPE marks were available in each sampled school was used in the study. The sample yielded a total of 1391 students from 16 secondary schools, 607 males and 784 females.

\subsection{Data Analysis}

Data was collected using a researcher made profoma which included a column for KCPE score, KCSE score and students' gender (see Appendix 2). The scores were obtained from data banks of the sampled schools. In this study, data analysis was quantitative. The collected data was analyzed using descriptive statistics namely scatter plots. Scatterplots indicated whether KCPE and KCSE were positively or negatively related. Inferential statistics including correlation and regression analyses were also used. Pearson's product moment correlation coefficients were determined to show the strength of relationship between KCPE and KCSE scores for various sub-groups in the study.

Simple linear regression analysis with KCSE scores as the dependent variable and KCPE scores, as the independent variables were conducted for different gender. A linear regression equation was determined in each case which could be used to predict mean KCSE scores from the independent variable (KCPE scores) in the regression model.

\section{Results and Discussion}

\subsection{Results}

\section{Relationship between KCSE and KCPE scores for male and female learners}

In order to determine the gender differences in the KCPE-KCSE relationship, a scatterplot for KCSE scores against KCPE scores disaggregated by gender was constructed (see Fig. 1). 


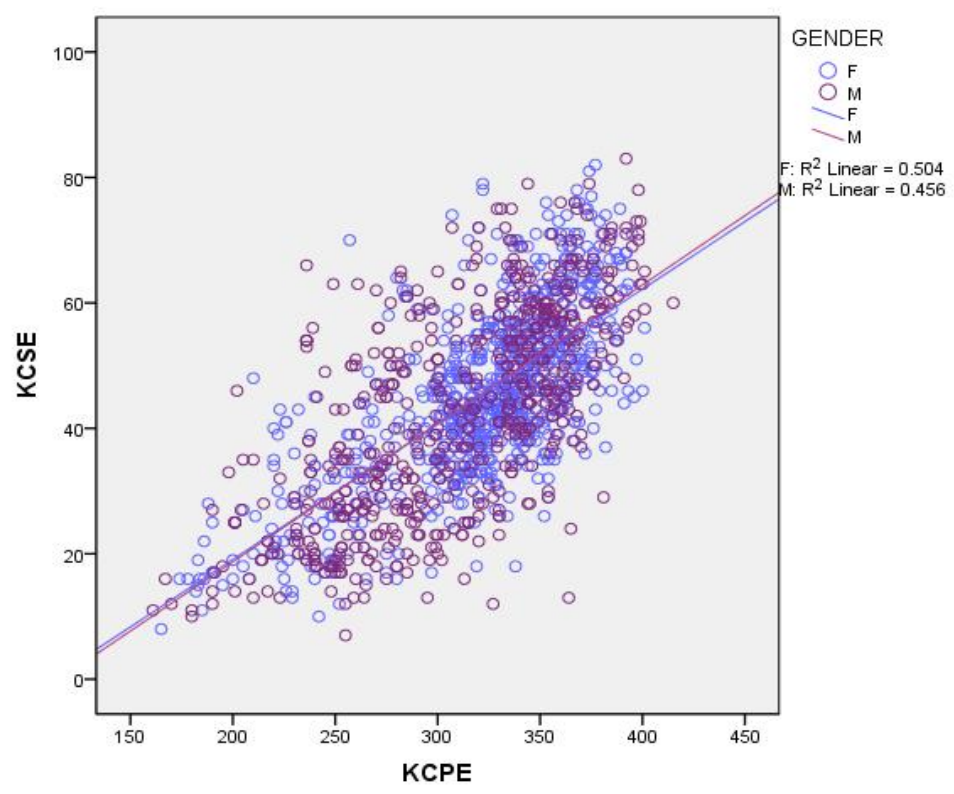

Figure 1. Bivariate scatter plots of KCSE against KCPE scores for male and female students Key: Gender F=Female; M=Male.

Source: Field Data.

The scatter plot in Fig.1 shows the relationship between KCSE and KCPE scores for both male and female learners. The slopes of the scatterplots for females and males were very close, indicating that KCPE scores could predict KCSE scores almost equally for both females and males. In order to obtain more information on the KCSE-KCPE relationship between male and female learners, Pearson's correlation coefficients for both gender were computed as shown in Table 1.

Table 1. Pearson's correlation coefficients between KCSE and KCPE for male and female students

\begin{tabular}{|c|c|c|c|c|}
\hline \multicolumn{3}{|c|}{ GENDER } & KCPE & KCSE \\
\hline \multirow[t]{5}{*}{ Female } & \multirow[t]{2}{*}{$\mathrm{KCPE}$} & Pearson Correlation & 1 & $.710 * *$ \\
\hline & & Sig. (2-tailed) & & .000 \\
\hline & \multirow[t]{3}{*}{ KCSE } & Pearson Correlation & $.710 * *$ & 1 \\
\hline & & Sig. (2-tailed) & .000 & \\
\hline & & $\mathrm{N}$ & 784 & 784 \\
\hline \multirow[t]{5}{*}{ Male } & \multirow[t]{2}{*}{$\mathrm{KCPE}$} & Pearson Correlation & 1 & $.675^{* *}$ \\
\hline & & Sig. (2-tailed) & & .000 \\
\hline & \multirow[t]{3}{*}{ KCSE } & Pearson Correlation & $.675 * *$ & 1 \\
\hline & & Sig. (2-tailed) & .000 & \\
\hline & & $\mathrm{N}$ & 607 & 607 \\
\hline
\end{tabular}

**. Correlation is significant at the 0.01 level (2-tailed).

Source: Field Data. 
Pearson's product moment correlation found a strong correlation between KCPE and KCSE for both male and female students. However the correlation was slightly stronger for females $(\mathrm{r}=.710 ; \mathrm{n}=784 ; \mathrm{p}<0.05)$ than for males $(\mathrm{r}=.675 ; \mathrm{n}=607 ; \mathrm{p}<0.05)$ as shown in Table 1 . This implied that KCPE scores was a better predictor of KCSE scores for females than for males.

The preliminary results on correlation however needed further scrutiny to ascertain whether the difference between $r$ values for females and that of males was statistically significant. This was done by first converting the $r$ values into $z$ values using a standardized table (see appendix 1), after which the following formula given by Pallant (2007) was used to calculate the observed $\mathrm{z}$ value $\left(\mathrm{z}_{\mathrm{obs}}\right)$;

$$
\mathrm{z}_{\mathrm{obs}}=\frac{z_{1}-z_{2}}{\sqrt{\frac{1}{N_{1}-3}+\frac{1}{N_{2}-3}}}=\frac{.887-.820}{\sqrt{\frac{1}{784-3}+\frac{1}{607-3}}}=\mathbf{1 . 2 3 6 5}
$$

Where $\mathrm{z}_{\mathrm{obs}}=$ the observed $\mathrm{z}$ value

$\mathrm{z}_{1}=$ the $\mathrm{z}$ value for female correlation coefficient

$\mathrm{z}_{2}=$ the $\mathrm{z}$ value for male correlation coefficient

$\mathrm{N}_{1}=$ sample size for females

$\mathrm{N}_{1}=$ sample size for males

The decision rule: if $-1.96<\mathrm{z}_{\mathrm{obs}}<1.96$, correlation coefficients are not significantly different (Pallant, 2007).

From the above calculation $\mathrm{z}_{\mathrm{obs}}$ value of 1.2365 falls within the range of -1.96 and 1.96 meaning that the difference between correlation coefficients between KCSE and KCPE for male and female students were not statistically significant. Further scrutiny of the difference in the relationship between KCSE and KCPE was done using regression analysis as shown in Table 2.

Table 2. Regression analysis of KCSE scores on KCPE scores for male and female students

\begin{tabular}{|l|c|c|c|c|c|c|c|}
\hline Gender & Model & $\mathrm{R}$ & $\mathrm{R}^{2}$ & Adjusted $\mathrm{R}^{2}$ & $\begin{array}{c}\text { Standard Error } \\
\text { estimated }\end{array}$ & $\mathrm{F}$ & Sig \\
\hline Female & 1 & .710 & .504 & .503 & 9.912 & 793.441 & .000 \\
\hline Male & 1 & .675 & .456 & .455 & 12.203 & 194.843 & .000 \\
\hline & Model & $\begin{array}{c}\text { Unstandardized } \\
\text { Beta }\end{array}$ & $\begin{array}{c}\text { Coefficient } \\
\text { Standard error }\end{array}$ & $\begin{array}{c}\text { Standardized } \\
\text { Beta }\end{array}$ & $\mathrm{t}$ & $\mathrm{Sig}$ \\
\hline Female & 1 (constant) & -23.971 & 2.464 & .710 & -9.728 & .000 \\
\hline & KCPE & .215 & .008 & & 28.168 & .000 \\
\hline Male & 1 (constant) & -25.422 & 3.073 & .675 & -8.273 & .000 \\
\hline & KCPE & .221 & .010 & & 22.529 & \\
\hline
\end{tabular}

$\mathrm{CI}=95 \% ; \mathrm{N}($ females $)=784 ; \mathrm{N}($ males $)=607 ;$ Total $\mathrm{df}($ females $)=783 ;$ Total $\mathrm{df}($ males $)=606$

Source: Field Data. 
Simple linear regression was used to assess the ability of KCPE scores to predict KCSE scores for male and female learners. Preliminary analyses were conducted to ensure no violation of the assumptions of normality and linearity. From the outcome shown on Table 2, $\mathrm{R}^{2}$ for females $=.504, \mathrm{~F}(1,783)=793.44, \mathrm{p}<0.05$. On the other hand, $\mathrm{R}^{2}$ for males $=.456, \mathrm{~F}$ $(1,606)=507.57, \mathrm{p}<0.05$. This implied that for females $50.4 \%$ of the variance in KCSE scores could be explained by the KCPE scores while for males, $45.6 \%$ of the variance in KCSE scores could be explained by the KCPE scores. The remaining $49.6 \%$ of the variance in KCSE scores for females and $54.4 \%$ for males could be explained by other factors other than KCPE scores. These preliminary results therefore indicate that the KCPE scores for females had slightly more effect on their KCSE scores compared to males.

The Univariate regression analysis results shown on Table 2 further indicates unstandardized coefficients of .215 for KCPE for females and .221 for males. The $t$ values of 28.168 for females and 22.529 for males and their significance of 0.000 (less than 0.05 level) showed that the score for both male and female in KCPE had a major impact on their KCSE scores. The values of the unstandardized coefficients imply that one unit increase in the female students KCPE scores results in a corresponding increase in their KCSE scores by 0.215 units. Similarly, one unit increase in KCPE scores for males results in a corresponding increase in KCSE scores by 0.221 units.

Using the unstandardized beta values and constants for KCPE, regression equations were drawn for both females and males as follows; $y=0.215 x-23.971$ for females and $y=0.221 x$ -25.422 for males where $y$ is the KCSE scores and $x$ is the KCPE scores of the learners. This implies that given circumstances similar to those in Kisii Central, the above equations can be used to predict learners' KCSE scores early from their KCPE scores.

\subsection{Discussion}

The findings illustrated in Fig. 1, Tables 1 and 2 are consistent with that of Othuon and Kishor (1994) in South Nyanza region which revealed that the examinee's sex did not significantly influence KCPE-KCSE relationship, although boys generally showed higher mean achievement levels in KCSE than girls.

On the other hand, a study by Jagero (2013) found girls to exhibit a higher correlation coefficient between KCPE and KCSE performance in one private school in Western Kenya, although the study sample was only 110 learners from a single school. The study by Jagero (2013) may therefore not be generalized due to the purposive sampling procedure used, making the sample less representative of the population. Another study done by Komba, Kafanabo, Tryphone and Kira (2013) in Tanzania found girls to exhibit a higher relationship $(r=0.726)$ between form two examination scores and form four certificate examination scores than for boys $(\mathrm{r}=0.613)$. When school category was considered, however, boys in day school showed a higher correlation $(\mathrm{r}=0.65)$ between the two examinations than girls in day schools $(\mathrm{r}=0.442)$.

Hall (2015) in a study to examine the validity of secondary school entrance scores in predicting academic success of secondary school aged students, found a stronger relationship 
between the scores on Barbados Secondary School Entrance Examination (BSSEE) and that of Caribbean Secondary Education Certificate (CSEE) for males than for females. This concurs with a study in Mosocho division of Kisii Central sub-county by Omenge and Nasongo (2010) that found girls to have a slightly lower academic achievement than boys. This was attributed to involvement in domestic chores by girls which impacted negatively on their academic achievement.

The studies by Jagero (2013) and Komba, Kafanabo, Tryphone and Kira (2013) simply gave the $r$ values for the relationship between KCSE and KCPE scores without testing whether the differences in the correlation coefficients given were statistically significant. This may point to some weakness in the two studies.

The findings of the study in Kisii Central sub-county point to the fact that the small difference in the relationship between KCSE and KCPE scores for male and female learners was not statistically significant. This implies that the predictive validity of KCPE scores for KCSE scores did not differ for male and female learners. While earlier studies depict boys as superior to girls in academic achievement, this trend may be changing. This could be probably due to the society becoming more enlightened about the importance of education for both boys and girls. Besides, the current parents having a higher level of education than parents of a few decades ago, may have contributed to this current state by giving equal chances to their children in education regardless of their gender. KCPE is therefore a good predictor of KCSE scores regardless of whether the learner is male or female.

\section{Conclusions and Recommendations}

\subsection{Conclusions}

This study ended up with the conclusion that KCPE scores is a strong predictor of KCSE scores for both female and male students and there is no significant gender difference in the predictive validity of KCPE for KCSE scores in public secondary schools in Kisii Central Sub-County. This implies that a student scoring highly in the KCPE examination will score highly in the KCSE examination and vice versa, regardless of their gender.

\subsection{Recommendation}

From the findings of this study, the researcher recommended that there should be no preferential treatment of learners based on gender. Male and female learners should be equally encouraged to improve in their test scores as they showed no significant difference in the relationship between their KCPE and KCSE scores. Appropriate actions by the government and other stakeholders aimed at improving academic achievement for girls should therefore be applied to boys as well.

\section{Acknowledgements}

This study was supported by Maseno University, Kenya. Special recognition is given to Prof. John Agak and Prof Lucas Othuon, both of the Department of Educational Psychology, Maseno University for their professional guidance. 


\section{References}

Barthes, A. M., Nair, S., \& Malpade, D. (2000). Scientific, Technical and Vocational Education of Girls in Africa: A summary of 21 National Reports. Washington D. C: World Bank.

Hall, M. T. (2015). An examination into the validity of secondary school entrance scores in predicting the academic success of secondary aged students. Current Issues in Education, 18(1). Retrieved $\quad$ August $\quad 31, \quad 2015$ from http://cie.asu.edu/ojs/index.php/cieatasu/article/view/1343

Jagero, N. O. (2013). How Performance of students in Kenya certificate of primary education can predict their performance in Kenya certificate of secondary education. Educational Research International, 1(3), 11-19. Retrieved May 27, 2014 from http://www.print.savap.org.pk

Kashu, J. N. (2014). Survey on gender and academic performance in secondary schools in Kenya. University of Nairobi. Research project report. Retrieved from erepository,uonbi.ac.ke/.../Kasha_...

Komba, S. C., Kafanabo, E. J., Tryphone, D., \& Kira, E. S. (2013). The predictive validity of form two secondary education examination (FTSEE) on students' performance in the certificate of secondary education examination (CSEE) in Biology subject: A Tanzanian perspective. Journal of Education and Practice, 4(4), 236-246. Retrieved August 31, 2015 from http://www.iiste.org

Makworo, B. K., Wasanga, C. M., \& Olaly, W. (2014). Psychosocial factors that affect girls' academic performance in secondary schools in Kenyenya, Kisii County, Kenya. International Journal of Psychology and Counseling, 6(9), 119-132. Retrieved August 30, 2015 from http://www.academicjournals.org

Mensch, B., \& Lloyd, C. (1997). Gender differences in schooling expenses of adolescents in low-income countries: The case of Kenya. A paper presented for the National Academy of Sciences Committee on Population, Washington D. C.

Omenge, N. B., \& Nasongo, J. W. (2010). Effect of socialization with regard to gender roles on students' academic achievement in secondary schools in Kisii Central District, Kenya. Current Research Journal of Social Sciences, 2(6), 327-333.

Ondima, C. M., Nyamasege, D., Mogwambo, B. A., \& Ochoti, G. N. A. (2013). Regression analysis of entry scores (KCPE) and final performance (KCSE) in Kenya: A case of Nyamira District, Nyamira County, Kenya. Mathematical Theory and Modelling, 3(4), 7-18. International Institute of Science, Technology and Education. Retrieved May 262014 from http://www.iite.org

Othuon, L., \& Kishor, N. (1994). Hierarchical linear modelling of predictive validity: The case of Kenya certificate of primary education examination. Studies in Educational Evaluation, 20, 175-194. The University of British Columbia, Vancouver, Canada. 
https://doi.org/10.1016/0191-491X(94)90002-7

Pallant, J. (2007). SPSS survival manual: A step by step guide to data analysis using SPSS for windows (3rd ed). Open University Press.

Rippy, M. (2012). Research designs: Correlational.

Trochim, W. M. (2006). The Research Methods Knowledge Base (2nd ed.). Retrieved February 19, 2015 from http://www.socialresearchmethods.net

Ugwuda, S. O., \& Okechukwu, S. A. (2013). Predictive validity of NECO junior school certificate examination on students' achievement in NECO senior school certificate examination. Research gate.

\section{Appendix}

Appendix 1. Table of Transformation of Pearson's Correlation Coefficient $r$ to $z$ values

\begin{tabular}{|c|c|c|c|c|c|c|c|c|c|c|}
\hline$r$ & $z_{r}$ & $r$ & $z_{r}$ & $r$ & $z_{r}$ & $p$ & $z_{f}$ & $r$ & $z_{r}$ & $\frac{\text { Table } 11.1}{\text { Transformation }}$ \\
\hline .000 & .000 & .200 & .203 & .400 & .424 & .600 & .693 & .800 & 1.099 & of $r$ to $z$ \\
\hline .005 & .005 & .205 & .208 & .405 & .430 & .605 & .701 & .805 & 1.113 & \\
\hline .010 & .010 & .210 & .213 & .410 & .436 & .610 & .709 & .810 & 1.127 & \\
\hline .015 & .015 & .215 & .218 & .415 & .442 & .615 & .717 & .815 & 1.142 & \\
\hline .020 & .020 & .220 & .224 & .420 & .448 & .620 & .725 & .820 & 1.157 & \\
\hline .025 & .025 & .225 & .229 & .425 & .454 & .625 & .733 & .825 & 1.172 & \\
\hline .030 & .030 & .230 & .234 & .430 & .460 & .630 & .741 & .830 & 1.188 & \\
\hline .035 & .035 & .235 & .239 & .435 & .466 & .636 & .750 & .835 & 1.204 & \\
\hline .040 & .040 & .240 & .245 & .440 & .472 & .640 & .758 & .840 & 1.221 & \\
\hline .045 & .045 & .245 & .250 & .445 & .478 & .645 & .767 & .845 & 1.238 & \\
\hline .050 & .050 & .250 & .255 & .450 & .485 & .650 & .775 & .850 & 1.256 & \\
\hline .055 & .055 & .255 & .261 & .455 & .491 & .655 & .784 & .855 & 1,274 & \\
\hline .060 & .060 & .260 & .266 & .460 & .497 & .660 & .793 & .860 & 1.293 & \\
\hline .065 & .065 & .265 & .271 & .465 & .504 & .665 & .802 & .865 & 1.313 & \\
\hline .070 & .070 & .270 & .277 & .470 & .510 & .670 & .811 & .870 & 1.333 & \\
\hline .075 & .075 & .275 & .282 & .475 & .517 & .675 & .820 & .875 & 1.354 & \\
\hline .080 & .080 & .280 & .288 & .460 & .523 & .680 & .829 & .880 & 1.376 & \\
\hline .085 & .085 & .285 & .293 & .485 & .530 & .685 & .838 & .885 & 1.398 & \\
\hline .090 & .090 & .290 & .299 & .490 & .536 & .690 & .848 & .890 & 1.422 & \\
\hline .095 & .095 & .295 & .304 & .495 & .543 & .695 & .858 & .895 & 1.447 & \\
\hline . 100 & .100 & .300 & .310 & .500 & .549 & .700 & .867 & .900 & 1.472 & \\
\hline . 105 & .105 & .305 & .315 & .505 & .556 & .705 & .877 & .905 & 1.499 & \\
\hline .110 & .110 & .310 & .321 & .510 & .563 & .710 & .887 & .910 & 1.528 & \\
\hline .115 & .116 & .315 & .326 & .515 & .570 & .715 & .897 & .915 & 1.557 & \\
\hline 120 & .121 & .320 & .332 & .520 & .576 & .720 & .908 & .920 & 1,589 & \\
\hline .125 & .126 & .325 & .337 & .525 & .583 & .725 & .918 & .925 & 1.623 & \\
\hline .130 & .131 & .330 & .343 & .530 & .590 & .730 & .929 & .930 & 1.658 & \\
\hline .135 & .136 & .335 & .348 & .535 & .597 & .735 & .940 & .935 & 1.697 & \\
\hline .140 & .141 & .340 & .354 & .540 & .604 & .740 & .950 & .940 & 1.738 & \\
\hline .145 & .146 & .345 & .360 & .545 & .611 & .745 & .962 & .945 & 1.783 & \\
\hline .150 & .151 & .350 & .365 & .550 & .618 & .750 & .973 & .950 & 1.832 & \\
\hline 155 & .156 & .355 & .371 & .555 & .626 & .755 & .984 & .955 & 1.886 & \\
\hline 160 & .161 & .360 & .377 & .560 & .633 & .760 & .996 & .960 & 1,946 & \\
\hline .165 & .167 & .365 & .383 & .565 & .640 & .765 & 1.008 & .965 & 2.014 & \\
\hline .170 & 172 & .370 & .388 & .570 & .648 & .770 & 1.020 & .970 & 2.092 & \\
\hline .175 & .177 & .375 & .394 & .575 & .655 & .775 & 1.033 & .975 & 2.185 & \\
\hline 180 & 182 & .380 & .400 & .580 & .662 & .780 & 1.045 & .980 & 2.298 & \\
\hline . 185 & .187 & .385 & .406 & .585 & .670 & .785 & 1.058 & .985 & 2.443 & \\
\hline .190 & .192 & .390 & .412 & .590 & .678 & .790 & 1.071 & .990 & 2.647 & \\
\hline 195 & .198 & .395 & .418 & .595 & .685 & .795 & 1.085 & .995 & 2.994 & \\
\hline
\end{tabular}

Source: McCall (1990); originally from Edwards, A. L. (1967). Statistical methods (2nd edtion). Hoft, Rinehart \& Winston 


\section{Appendix 2. Manual Data Collecting Pro forma}

\begin{tabular}{|c|c|c|c|}
\hline \multirow{3}{*}{\multicolumn{2}{|c|}{$\begin{array}{l}\text { NAME OF SCHOOL. } \\
\text { NO. OF } 2010 \text { KCSE CANDIDATES. } 28 . . . . .\end{array}$}} & \multicolumn{2}{|c|}{ CATEGORY: (Dav, Boarding, Day \& Boarang) } \\
\hline & & \multicolumn{2}{|c|}{ LOCATION: (Urban, Rural) } \\
\hline & & \multicolumn{2}{|c|}{ SIZE: $\quad$ (Small Medium, Large) } \\
\hline KCSE INDEX NO. & GENDER & KCPE SCORE & KCSE SCORE \\
\hline $703 \times x \times 001$ & 1 & 300 & $c-36$ \\
\hline $703 \times x \times 002$ & 2 & 257 & c 44 \\
\hline 003 & 2 & 341 & 69 \\
\hline 004 & 2 & 291 & 23 \\
\hline 005 & 1 & 255 & 30 \\
\hline 006 & 2 & 217 & 22 \\
\hline 007 & 2 & 261 & ct 39 \\
\hline 008 & 2 & 201 & Dt 25 \\
\hline 009 & 2 & 238 & $c-35$ \\
\hline 010 & 2 & 254 & Dt 26 \\
\hline 011 & 2 & 252 & Dt 26 \\
\hline 012 & 2 & 249 & D 18 \\
\hline 0,3 & 1 & 224 & $D \quad 18$ \\
\hline 014 & 1 & 232 & 1) 20 \\
\hline 015 & 2 & 222 & 20 \\
\hline 016 & 1 & 219 & D 20 \\
\hline 017 & 1 & 265 & $D-16$ \\
\hline 018 & 1 & 186 & $17-16$ \\
\hline 019 & 2 & 253 & $D-17$ \\
\hline 020 & 2 & 252 & $D-17$ \\
\hline 021 & 1 & 200 & $D-16$ \\
\hline 022 & 1 & 183 & $D-15$ \\
\hline 023 & 1 & 248 & $D-17$ \\
\hline 024 & 1 & 190 & $D-17$ \\
\hline 025 & 1 & 226 & $D-14$ \\
\hline 026 & - & - & - \\
\hline 027 & 1 & 240 & $D-16$ \\
\hline 028 & 1 & 208 & $D-16$ \\
\hline$\ldots+\cdots$ & $\infty \quad \ldots \ldots$ & $\ldots .$. & $\therefore \quad \therefore \quad \ldots$ \\
\hline & & & \\
\hline
\end{tabular}

\section{Copyright Disclaimer}

Copyright for this article is retained by the author(s), with first publication rights granted to the journal.

This is an open-access article distributed under the terms and conditions of the Creative Commons Attribution license (http://creativecommons.org/licenses/by/3.0/). 